\title{
FOOD, SERVICE AND CONSERVATION IN A PROVINCIAL HOSPITAL.*
}

By J. C. MITCHELL, M.D.,

Superintendent Hospital for Insane, Brockville, Ont.

The problem of satisfying the hunger of the inmates of a provincial or state hospital at a moderate expense, and with a menu nutritive, varied and palatable, cannot be overestimated. Since the prices of all food products have advanced to such a height during the past two years (owing to the demands made on us by the great war for freedom in which we are all so zealously engaged), this question has become a very vital one.

During the past seven years those having to do with this question in our hospital, have made a greater effort than ever before to vary the monotony of the meals. "Variety is the spice of life," and this is notably so in feeding the large number we have in our various hospitals. A large number of our patients are so advanced in dementia that the quality or kind of food does not appear to make much difference to them. Many of them are gluttonous and will eat not only the portion allotted to them but that belonging to their neighbors if they can lay hands on it.

\footnotetext{
“ Ne'er looks to heaven amidst his gorgeous feast, But with besotted base ingratitude Crams, and blasphemes his feeder."
}

We always have, however, a large number to whom the kind and quality of foods is very essential. We all notice in going through our wards, when we have some special change in the quality of the meal, how pleased the better class of patients are. A good and satisfying meal that appeals to them makes such a difference in their attitude, they are so much better natured, so much kinder with each other than they are when they have a meal that is insufficient, poor in quality or served in such a way that it arouses a feeling of resentment. Food, no matter how plain in quality if well cooked, seasoned, and properly served appeals to our senses in such a way that it makes a great difference to our daily lives. It must be ample in quantity and bulk, and served with fruit and

* Read at the seventy-fourth annual meeting of the American MedicoPsychological Association, Chicago, June 4-7, 1918. 
vegetables. If properly cooked and tastefully served it becomes a very valuable therapeutic agent in our type of hospitalspatients are so much more accessible and respond so much better to treatment.

As carefully as we have looked into this subject, and as much time and thought as we have given to its consideration, we are not able to satisfy ourselves that we are doing the best we can for our patients.

For many years the diet in our hospital was extremely monotonous. Breakfast consisted of porridge, bread and butter and tea. Dinner-boiled beef (with the exception of Friday when fish was furnished for most of the patients), potatoes, one or more vegetables and boiled rice or a pudding. Supper-bread, butter and tea with stewed figs, prunes or syrup and cheese on Sunday evening. On Thanksgiving Day we served pork, and on Christmas Day fowl and an elaborate dinner, and plenty of eggs for all at Easter. These were about all the changes given during the year. In I9I I this diet was varied a good deal by furnishing an occasional soup, and pork in some form for dinner once a week. We raised our own pigs, and our fat cattle were purchased for us, and they were butchered and prepared at our own institution. Fish for Friday was so difficult to procure fresh in summer that we began the use of canned salmon. This we found worked so well that we have kept it up ever since. We have found it to be cheaper and more palatable and we serve it in different waysoccasionally cold but usually heated and served with white sauce.

In 1914 our Department (the provincial secretary's) in the Ontario Government instituted a plan to be followed in all our hospitals by which we were to adhere to the basic dietary ration table, as prepared for the New York state hospitals. The plan issued to us embraced not only the patients but the officers and employees. We still follow this ration table but have made some changes as we found the bread was not sufficient to satisfy our people. We issue to patients a daily bread ration of 14 to 15 ounces, meat 4 ounces, beans $I_{2} \frac{1}{2}$ ounces, butter I 1 ounces, rolled oats I ounce, sugar I 1 ounces, cheese $1 \frac{1}{4}$ ounces, tea $\frac{1}{5}$ ounce and potatoes 7 ounces. We find this ration works out very satisfactorily. We have a large blackboard, placed in a prominent part of the central kitchen, which gives at a glance the number of 
patients in residence. The census is altered on the 7 th, $14^{\text {th, }}$ and 2Ist, and last days of each month.

We also inaugurated a system for looking after the waste. All the wards return to the kitchen, after each meal, the usable and unusable food. This is weighed carefully and a strict account kept, and the usable food (except the unused cooked cereals which are added to the soups) are returned to the wards from which they came, to be again made use of, and the unusable food going to the garbage. We find this weighing of waste of great benefit to us financially as there is not nearly so much garbage as formerly. The garbage is removed to the piggery, where it is thoroughly steamed and made use of for consumption in that department.

We have a large farm in connection with the hospital that is situated two miles from the institution. We have there 30 resident patients ( 5 females and 25 males) and 13 of a staff. This staff consists of the husband and wife as supervisors in that department, and the balance consisting of employees who are engaged in farm work. We do not have the waste returned from there, but it is very carefully looked after and properly made use of. The population of the farm is exactly under the same ration standard as the other parts of the hospital, with the exception that owing to an increased demand for food on the part of those working in the open air there, the patients are given a larger amount of meat daily than we give at the main building.

During the year 1917 we had a Dominion Food Controller (Hon. W. J. Hanna) appointed, and we made some changes in order to conform with his regulations. At present our menu for patients is about as follows: Breakfast-cereal, either oat or corn meal, tea, bread and butter and an egg to those requiring extra diet. On Sundays we serve coffee instead of tea. Dinner on Sundays-headcheese, bologna sausage, or provincial ham with potatoes, vegetables, rice pudding and tea. On Mondays, Wednesdays and Thursdays either an Irish or brown stew well provided with vegetables, also potatoes with bread and butter and tea and a rice or bread pudding as dessert. On Tuesdays we serve soup made of stock (from left-over bones, meat trimmings, etc.), beans (with a little pork), vegetables and a dessert. On Fridays, bean or pea soup (which is rich in proteins), with canned salmon, the usual vegetables, and pickled red cabbage or sauerkraut. On 
Saturday a boiled meat with the usual accompaniments. The suppers are bread, butter and tea with cheese on Sunday nights, and during the week, one night creamed carrots and peas, another boiled onions with creamed sauce, marmalade, and a third night with macaroni and cheese. The other evenings syrup or sauce is served, and sauerkraut with some evening meals. Of course at all meals green vegetables such as lettuce, etc., are served when available.

The menu on Sundays for the staff for breakfast is: Either corn flakes or shredded wheat; Mondays, Wednesdays, Thursdays and Saturdays-a cereal, toast, sauce or marmalade, and either tea or coffee. Tuesdays and Fridays-(meatless days) eggs are served for breakfast. Dinners (four days a week) -roast meat with potatoes and vegetables; vegetable stew on Tuesday, and on Friday fresh fish. On Sundays and Tuesdays as dessert we serve ice cream (skimmed milk) or a water ice; various desserts are served up on the other days. Saturdays they frequently have sausage and sauerkraut. Supper for the staff consists of cold meat with potatoes for five nights in the week usually with pickles or a salad, bread, butter, and tea, and the other nights cheese or baked beans.

The officers' table differs very little from that of the rest of the staff with the exception of fresh fruit in season, and when available poultry or some change of meat on Sundays.

On Fridays we use for the patients 130 cans of salmon and when meat is used from I 40 to 175 pounds. This year we had such a large quantity of cabbage that we put down five tons of sauerkraut. The amount of meat, either bologna or headcheese, used on Sundays is about $\mathrm{I} 60$ pounds. This is prepared at our provincial abattoir, Guelph, from which all our meats have been shipped since I9I 5 .

We might mention that we grow a very large quantity of strawberries, sufficient to feed our patients a number of times during the season. The same may be said of asparagus. Tomatoes and fall apples are usually a heavy crop. From the time they first come in until late in the fall our patients are furnished with all they care to eat (both raw and cooked); they are perishable products so they consume a great many of both these articles. In the spring of the year we always procure a large quantity of maple syrup at a reasonable price which is a great treat for all. 
With the increased price of food products we find it more difficult to serve a good evening meal and our experience has been that apples at even $\$ 5.00$ or $\$ 6.00$ a barrel are cheaper than nearly anything else we can provide so that this last winter we have served a good deal of apple sauce for supper. They are usually prepared by boiling the apples whole and putting them through an electric pulper which extracts the skin and core. This, sweetened, is very palatable. Occasionally we have served baked apples to all. In order to prevent this becoming monotonous we have also used prunes, evaporated peaches, and as mentioned in our menu, macaroni with white sauce made from skimmed milk.

We have three special diet kitchens, one in the male admission ward and two in the female admission wards, one being in the new Reception Hospital. From these places food is prepared and served to the patients, independent of the main kitchen. The food served here is that ordered by the physicians in charge for the newly admitted patients, and for those who are ill, and require special care and diet; the main kitchen of course being entirely under the chef. We have no special dietitian as is provided in a good many hospitals but our storekeeper has charge of all food supplies and issues the amount of special diet to those preparing them in the different locations. The nurses who are in their intermediate year have charge of these diet kitchens and they are on duty there for two months. In this way all nurses get an education in preparing diets and we find that this plan works out well.

We have a dining-room in connection with each ward. The largest number we have in any one room is 70 patients. Our dining-rooms are well lighted, bright and cheerful and the rooms are kept in excellent repair; the walls painted a light color and everything done to make these rooms as tasty as possible. We have small tables that accommodate about eight so we can group congenial people together. We have a special warming closet in each dining-room so that in cold weather we always have hot plates ready for use.

Our gardener takes a great interest in our wards and diningrooms and all our tables the greater part of the year are furnished either with plants or bouquets. During this past winter there has not been a single day but what our wards have been well supplied with plants or flowers. This adds very much to the attractiveness of the rooms. 
Patients' meals are served at 6.30 a. m., I I.30 a. m., and 5.30 p. m. We have meals at these hours so as not to conflict with the meal hours of the nurses and attendants. All the nurses and attendants are on duty at meal time and are expected to give their services exclusively to seeing that the patients have proper attention.

In the admission and hospital wards there are a great many trays to be served to those who are confined to bed. Everything possible is done to see that our patients get their allowance of food. Patients who are inclined to steal the food from others are placed at tables together and are especially watched over. Working patients are so placed that they get an extra amount of food to those who do nothing. Patients all come to the dining-room together at a given signal and no one is allowed to leave until all are through with their meals and the cutlery, etc., is properly gathered up to see that none is carried off.

In order to give some idea of the per capita cost and its gradual increase we have taken one day, May 2 in each year, covering five years.

May 2, 1914, the cost of meals served was $\$ 91.69$ for 840 persons. The total number of meals served was 2520 ; averaging .0364 per meal. For the officers, nurses and attendants and employees we served 369 meals ; averaging .0587 ; for the patients, averaging .0326.

May 2, 1915, taking the same number of persons our total cost was $\$ 105.65$ per day; the total per capita, .0419. The officers, nurses and attendants, .0672 , and the patients, .0376 .

May 2, 1916, the total cost was \$110.16, the cost per meal, .0437. Officers, nurses and attendants, .0722; patients, .0388.

For the year 1917 the cost per day was $\$ 135.31$ and the cost per meal, .0537. The officers, attendants, etc., .0859 and for the patients, .0482. For the same date of the present year the cost per day was $\$ 154.52$; total cost per meal, .061 3. For the officers, attendants, etc., .0984 and for patients, .0549.

You will see from this the gradual increase since the war began and how much the prices have gone up, practically 75 per cent. I may state that the rate of potatoes was the same during these four years as they were raised on our farm and the price charged was 40 cents per bushel. Each year we have had to buy potatoes from early in May, which made our cost per capita much more. This year our farm has produced enough to carry us through 
until we have potatoes again. We grow so many vegetables and furnish so much from our farm for patients that the rates quoted are considerably lower than if we had had to purchase all these goods.

I have brought with me a sample of how our prices are worked out in our Ontario institutions. This work is all directed from the management at the Parliament buildings.

The proper cooking of food, its service and conservation are among the great problems with which we have to deal. Where there is no regular dietitian the chef practically has to be superintendent of his department. He plans the menus, the requisitions, and the work for his department (the physician being responsible for the special diets). He has to be responsible for his kitchen, cold storage and general equipment. It is necessary that he should be constantly on the alert to see that everything is kept in proper condition, that his assistants do their work in a cleanly and economical manner; and to see that the food is properly cooked, and sent from the kitchen so as to be served in a nice manner when it arrives from the wards. We do not make our chef responsible for the food after it leaves the kitchen. The supervisor of each ward is responsible for the proper service of the food. when it is brought in. It is very important that the chef be a competent person, capable of working harmoniously with the officers of the institution, to oblige them whenever it is possible and make everybody feel that they are working together in the interest of all.

We all realize the importance of serving a well-balanced diet. There are none of us probably but have seen patients suffering from the lack of some important article (possibly vitamines) in their diet that they probably do not care to eat, and those looking after them were not solicitous enough for their welfare to see that they were supplied with the kind of diet that is requisite for good health. Personally, I have seen quite a number of cases of scurvy arise in patients who refuse to eat vegetables. Their peculiarities were not reported, with the result that I have mentioned.

Since writing the foregoing I have received a brochure entitled "A Proposed Basis for a Dietary for Hospital for the Insane to Meet War Conditions," prepared by H. J. Sommer, M. D., and P. Saha, M. D., Blair County Hospital of Hollidaysburg, Pa. 
This pamphlet meets the food problem in an excellent manner and has arranged a number of proposed dietaries for working and custodial patients. I think it merits our careful attention and will give us a basis for working out many reforms in our food conditions, as it is all on a scientific basis.

In Ontario, Canada, the following letter has been sent to the superintendents of all the county houses of refuge and all the institutions receiving a government grant. It speaks for itself :

“Toronto, March 22, I9I8.

“My dear Superintendent :

"One year ago to-day a letter was addressed to you asking your help, and saying 'The need for increased production of food is real and urgent.' A splendid response was made to that appeal.

"If the need of food was great last year, it is ten times greater this year. Last year Germany only was on rations. This year Britain is on rations, France is on rations, Italy is on rations. The British are denying themselves and going hungry. Starvation stares the French, Belgians, and Serbians in the face. Famine threatens the Italians.

"Our Allies depend on Canada and the United States for food. They are trusting to us. We must not fail them.

"If you have a farm, or if you know anybody who has a farm, see that at least five more acres of wheat are grown on that farm in 1918 than in 1917 ; and grow in your garden all the potatoes, peas, beans, beets, onions, carrots, parsnips and other food that you can grow, and do not let one foot of earth lie idle this year anywhere in your township, village, town or city.

"Every head of cattle, every sheep, every pig, every chicken we can raise is wanted, and badly wanted.

"Under Almighty God our hope of final victory and rightful peace is in the hands of our farmers, as truly as it is in the hands of our munition workers and in the hands of our fighting men.

"Everybody can help-men, women and children.

"Do not waste any food-not a crumb.

"Be a leader and get everybody to help."

This work requires us, no matter what our nationality, to work together, not only in feeding our people properly, but at the same time by paying careful attention to conservation. Save a certain amount and the multiplication of that saved in all our institutions will be a very great asset for our nations.

Need I say more? Only this! In carrying out the solemn duty of doing our very best for the dear people God, in His Providence, has committed to our care, that we realize in like manner the importance in this crisis of doing all we possibly can for food production, and especially food conservation. 